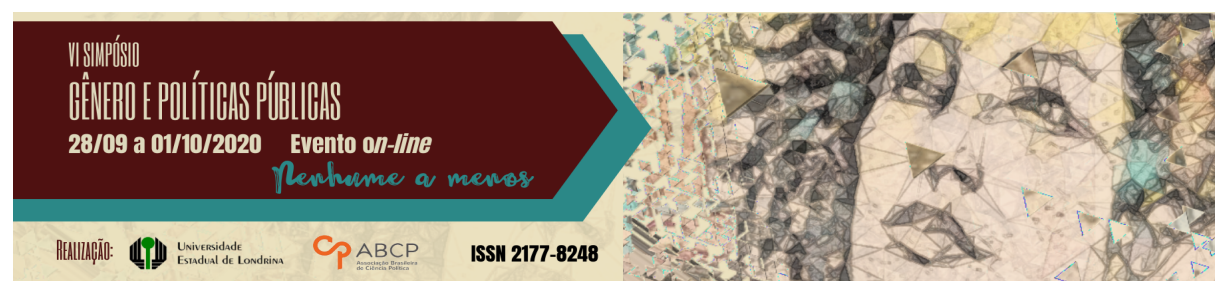

\title{
Os fundamentos liberais conservadores da ideologia de gênero e do programa "escola sem partido": a práxis educativa como alternativa no ensino de sociologia crítica
}

Juliana Guidi Magalhães ${ }^{1}$

\section{Resumo}

A pesquisa consiste numa síntese da dissertação de mestrado apresentada no Programa Mestrado Profissional de Sociologia em Rede Nacional e possui o objetivo principal de analisar os desafios relativos à prática docente no tocante ao ensino da Sociologia no Ensino Médio, considerando o atual contexto político, social e econômico de evidente ofensiva liberal conservadora no Brasil, mediante o Programa "Escola sem Partido" e a construção da narrativa de "ideologia de gênero". Apresentando o atual contexto e apontando para a necessidade de uma alternativa educacional, a pesquisa propôs uma reflexão sobre a aula como práxis educativa, como ferramenta política e educacional de enfrentamento do supradito discurso e de defesa do caráter científico da sociologia. A proposição teórico-metodológica alternativa para efetivar esta reflexão se pautou na "Metodologia de Mediação Dialética - M.M.D", desenvolvida pela professora e pesquisadora Maria Elisa Brefere Arnoni, professora do Departamento de Educação - IBILCE de São José do Rio Preto/SP.

Palavras-chave: sociologia; ideologia de gênero; práxis.

\section{The conservative liberal fundamentals of gender ideology and the "escola sem partido" program: educational praxis as an alternative in the teaching of critical sociology}

1 Universidade Estadual Paulista, Mestra em Sociologia e bacharel/advogada em Direito, jujumagalhaes33@gmail.com/juliana.magalhaes@unesp.br

GT 08 - Gênero, educação e escola 


\begin{abstract}
The research consists of a synthesis of the master's dissertation presented in the Professional Master's Program in Sociology in the National Network and has the main objective of analyzing the challenges related to teaching practice in relation to the teaching of Sociology in High School, considering the current political, social and an evident conservative liberal offensive in Brazil, through the "Escola sem Partido" Program and the construction of the "gender ideology" narrative. Presenting the current context and pointing to the need for an educational alternative, the research proposed a reflection on the classroom as an educational praxis, as a political and educational tool to face the abovementioned discourse and to defend the scientific character of sociology. The alternative theoretical and methodological proposition to carry out this reflection was based on the "Dialectic Mediation Methodology - M.M.D", developed by professor and researcher Maria Elisa Brefere Arnoni, professor at the Department of Education - IBILCE of São José do Rio Preto / SP.
\end{abstract}

Keywords: sociology; gender ideology; praxis.

\title{
Introdução
}

No tocante ao cenário da educação brasileira, o aspecto conjuntural é de evidente investida dos grupos dominantes privatistas e conservadores, sendo, também, uma realidade crescente em todos os países do mundo. Este contexto ressalta a importância de uma posição de enfrentamento de todos os trabalhadores e trabalhadoras da educação em relação às ofensivas, através da crítica e da proposição de uma alternativa emancipadora.

É deste modo, que o capital globalizado contemporâneo tem acarretado profundas transformações no interior das lutas de acesso à cidadania $^{2}$ e, sobretudo na luta para a manutenção de direitos

\footnotetext{
2 Acerca do conceito de emancipação humana e emancipação política muitos são os autores brasileiros que debatem sobre o tema, tomando como respaldo metodológico a teoria marxiana. Contudo, evidencia-se a distinção realizada por Ivo Tonet (2018, p. 901), que indaga "o que é emancipação humana? A palavra emancipação evoca, de modo muito geral, a ideia de liberdade. Essa liberdade pode ser entendida em sentido jurídico - a liberdade adquirida por menores de idade em relação aos seus pais ou tutores legais, - em sentido político - a liberdade obtida por uma nação ou região ou província face a outro poder político, - em sentido humano, isto é, a liberdade mais plena possível para o ser humano". Esta emancipação humana está associada à superação da sociedade de
} 
fundamentais como a educação pública e de qualidade. Neste aspecto, “o capital, sob a pressão de sua crise estrutural, está sendo forçado a retomar até as concessões que foi capaz de oferecer nas décadas de expansão keynesiana do pós-guerra a setores limitados dos trabalhadores (MÉSZÁROS, 2004, p. 34).

Para assegurar o direito à educação, emerge o desafio de estabelecer as contradições sociais e jurídicas no país no que tange a esta problemática, uma vez que os direitos, minimamente conquistados no bojo da sociedade capitalista, estão sendo suprimidos paulatinamente. Observa Mészáros que:

Hoje em dia, [o capital] não se pode garantir nem mesmo a conquista das demandas mais limitadas dos trabalhadores, dado o impacto insustentável nos custos do sistema global estruturalmente problemático. O local-regional está se tornando, atualmente, inseparável do global-internacional, para, em última instância, enfraquecer, e não reforçar, a dominação do trabalho pelo capital, contrária à propaganda interesseira da globalização capitalista (MÉSZÁROS, 2004, p.35).

Os fenômenos do capitalismo mundializado e as novas formas de ataques à educação podem ser notados pelos inúmeros projetos de lei propostos no Congresso Nacional, em assembleias legislativas e câmaras de vereadores, em todo o país. Todos estes projetos versam “que os valores de ordem familiar [têm] precedência sobre a educação escolar nos aspectos relacionados à educação moral, sexual e religiosa, vedada a transversalidade ou técnicas subliminares no ensino destes temas"3.

classes e de todas as formas de opressão/dominação; compreendendo que a simples emancipação política no bojo da sociedade capitalista equivale a conquista de liberdade nos limites impostos pela classe dominante. Continua Tonet, "quando Marx fala em emancipação humana está, claramente, se referindo a uma forma concreta de sociabilidade na qual a humanidade alcança o grau de liberdade mais amplo e profundo possível. Vale dizer, para Marx, emancipação humana equivale a sociedade comunista". 3 Destacam-se os PLs 7180/2014 e 7181/2014, ambos de autoria do deputado Erivelton Santana, à época filiado do PSC (Partido Social Cristão), ligado à igreja Assembleia de 
O que se pode notar é um esvaziamento significativo na educação brasileira, que se insere na lógica de sucateamento e privatização, elementos norteadores da política econômica neoliberal. Inúmeros agentes estão envolvidos neste novo projeto de Nação, os quais possuem como característica em comum: estabelecer uma hegemonia intelectual, que regula o comportamento e os anseios da juventude brasileira.

O projeto político em curso para educação não está dissociado do mesmo objetivo delineado pelo empresariado nacional, o qual encontrou no fundamentalismo religioso uma eficiente ferramenta de articulação e condução do consciente coletivo. A formação de expressões políticas conservadoras e liberais de movimentos, partidos e intelectuais aglutinam várias ideias regressivas no debate sobre proposições educacionais.

O projeto do movimento ESP [Movimento Escola sem Partido] é, antes de tudo, uma reação dos setores conservadores, encabeçados pela bancada evangélica, que visa ingerir-se na autonomia escolar e no exercício da docência, associando a educação formal com a informal como se sinônimas fossem e partissem do mesmo fundamento. Pretende, ainda, imiscuir a ideologia religiosa no ambiente escolar que, por princípio constitucional, é laico. Tudo isso é muito inovador e se choca contra valores que estão no único livro no qual os defensores do projeto se baseiam para fundamentar suas ideias anticientíficas" e, assim, “[...] a direita saiu do armário, literalmente. Presenciamos o avanço do irracionalismo na educação" (SOUZA; OLIVEIRA, 2017, p. 126). Lozano (2018) delineia de maneira bem didática o pressuposto do ESP:

Nada mais partidarizado que o Escola sem Partido. A pretexto de expurgar um suposto viés político à esquerda dos professores, seus militantes querem

Deus e membro da Frente Parlamentar Evangélica. A ficha de tramitação do projeto de lei na Câmara dos Deputados. Disponível em: https://www.camara.leg.br/proposicoesWeb/ fichadetramitacao?idProposicao=60672 2. Acesso em: 21 mar. 2019. 
extirpar da escola sua institucionalidade pública, de espaço de debate e formação acima e além das crenças familiares e valores religiosos de caráter privado. O verdadeiro pavor do Escola sem Partido é a inserção das crianças no mundo fora da família, que começa na escola. O que o movimento combate é a ideia de escola como espaço público, onde crianças e jovens vão necessariamente ao encontro da diferença, transcendendo a vida privada (LOZANO, 2018, p. 10).

Consoante ao pensamento marxista do filósofo húngaro, István Mészáros (2008), a educação como órgão social é, sobretudo uma dimensão societária essencialmente comprometida com os rumos da transição socialista, ainda mais quando se nota no processo educativo as metamorfoses do capital, a partir de inúmeras teorias pedagógicas, as quais camuflam a reprodução do sistema ideológico do capital. Ainda de acordo com o autor, a educação institucionalizada foi, até então, usada para

transmitir um quadro de valores que legitima os interesses dominantes, como se não pudesse haver nenhuma alternativa à gestão da sociedade, seja na forma 'internalizada' (isto é, pelos indivíduos devidamente 'educados' e aceitos) ou através de uma dominação estrutural e uma subordinação hierárquica e implacavelmente impostas (MÉSZÁROS, 2008, p. 35).

O filósofo analisa, antes mesmo desta abordagem sobre o papel da educação, a necessidade de uma transformação radical "do quadro social no qual as práticas educacionais devem cumprir as suas vitais e historicamente importantes funções de mudança, ou seja, Mészáros (2008, p. 25), adverte sobre a impreterível transcendência da ordem vigente, pois seria inócuo reformas pontuais na educação enquanto mantivermos "intactas as determinações estruturais fundamentais da sociedade como um todo com as exigências inalteráveis da lógica global do sistema de reprodução". 
Nesse passo, percebe-se que para o pensador torna-se impossível a coexistência de legitimar o conflito entre forças hegemônicas fundamentais rivais como alternativas viáveis entre si, "quer no campo da produção material, quer no âmbito cultural/educacional" (2008, p. 26).

A inviabilidade de se pensar um ideal educacional senão como instrumento para transição socialista, já que nunca será permitida alguma espécie de projeto para educação que seja diametralmente oposta aos objetivos da classe dominante. Neste caso, pode-se vislumbrar o caso da pedagogia revolucionária, no Brasil, como sendo um obstáculo para a pedagogia da hegemonia burguesa. Além do mais, Mészáros realiza a crítica às pedagogias que não buscavam solapar a base de reprodução material da sociedade burguesa.

\section{O engodo denominado narrativa da "ideologia de gênero" e o Programa "Escola sem Partido"}

O avanço das vozes conservadoras no debate político brasileiro, concedendo espaço e legitimidade ao discurso reacionário sobre a suposta "ideologia de gênero", estabelece a necessidade de compreensão do surgimento de tal narrativa ${ }^{4}$ construída de maneira dissociada de qualquer fundamento científico.

\footnotetext{
4 Vislumbra-se a necessidade de entender o conceito exposto de "narrativa" quando se tratar sobre "ideologia de gênero". Proposto por Paul Ricoeur, o conceito de narrativa contribui para (re)configurar o entendimento da ação humana; enxerta novos elementos temporais às configurações da ação. Interações diárias que se configuram (e resultam) em processos narrativos ocorrem a partir da articulação: memória, tempo e narrativa. Segundo o autor, "o tempo torna-se tempo humano, na medida em que está articulado de modo narrativo; em compensação a narrativa é significativa na medida em que esboça os traços da experiência temporal." (RICOEUR, 1994, p.17). Mais adiante, o trabalho indicará alguns elementos constitutivos desta narrativa de "ideologia de gênero", tendo como centralidade o discurso religioso e a sua apropriação por agentes públicos. Esta narrativa justificará articulações, manobras legislativas e políticas públicas voltadas para a dimensão de conservação da moral judaico-cristã e, sobretudo, para fundamentar um projeto privatista e inócuo de educação.
} 
A proficuidade do debate sobre a categoria de análise gênero ganhou espaço no cenário acadêmico norte-americano a partir da década de 1970, momento que estabeleceu as diferenças substanciais existentes entre as características fisiológicas do feminino e masculino e a sua constituição no mundo social. Deste modo, construiu-se a discussão que poria em curso uma verdadeira "revolução" quanto ao pensar sobre homem/mulher. Assinala-se que o conceito de gênero apresenta inúmeras controvérsias, mesmo para as autoras feministas, não sendo esta discussão o objetivo deste trabalho.

Nesta perspectiva, vislumbra-se o avanço conceitual-científico como uma ameaça aos status quo defendido pelos setores conservadores da sociedade, particularmente, os religiosos fundamentalistas, propondo uma efetiva "cruzada moral". Este embate entre os movimentos feminista/ LGBTI e segmentos cristãos é um fenômeno de caráter transnacional que se desenvolve desde a década de 90 do século passando, quando o ativismo feminista ganha espaço nas Conferências promovidas pela ONU (MACHADO, 2018).

Toni Reis (2017) exemplifica este pânico instalado socialmente com o objetivo único de ganhar terreno e distorcer o real significado dos estudos embasados no conceito "gênero", vez que "a ampla disseminação da falsa premissa da "ideologia de gênero", vista como a desconstrução dos papéis de gênero tradicionais e, por consequência, da família, dentro dos ambientes educacionais, despertou uma espécie de pânico moral, retrocesso e demonização do "inimigo" (REIS, 2017, p. 20).

A Igreja Católica, na Conferência Episcopal do Peru, expediu uma nota intitulada "A Ideologia de Gênero: seus perigos e alcances", em abril de 1998, cujo documento apresentou pela primeira vez o conceito de "ideologia de gênero" como resposta à Conferência Internacional sobre as Populações e Desenvolvimento, na cidade do Cairo, em 1994, e a IV Conferência Internacional sobre as Mulheres, na capital chinesa, em 1995. A Organização das Nações Unidas (ONU), idealizadora dos eventos, mostrou-se, notadamente, interessada na luta pela igualdade de 
gênero, podendo ser demonstrada pelas inúmeras campanhas e projetos promovidos pela Organização ${ }^{5}$.

Por outro lado, o Programa "Escola sem Partido", que nasceu da pretensão do advogado paulista e procurador do estado de São Paulo, Miguel Nagib, em 2004 e teve seu cerne na preocupação sobre uma hipotética educação "esquerdista", toma maior repercussão nacional quando incorpora esta pauta moral e estreita a relação com os segmentos religiosos em luta contra a "ideologia de gênero" nas escolas, acentuando ser este fenômeno uma criação "esquerdista" e, sendo assim, toda a forma de "doutrinação marxista" nas escolas, instalaria, consequentemente, o desarranjo da instituição familiar.

O professor Fernando Penna (2017, p.35) destaca o perigo inerente a este discurso propagado desde o ano de 2004 e, apenas há poucos anos, vem demonstrando sua real força por estabelecer relações com o poder legislativo com o fito de efetivar os interesses de setores privatistas da educação:

O discurso do Escola sem Partido não foi devidamente enfrentado, a meu ver, desde o momento em que ele surgiu, em 2004, justamente por

\footnotetext{
${ }^{5} \mathrm{Na}$ página da internet da ONU Mulheres-Brasil, pode-se compreender os objetivos elencados pela IV Conferência Mundial sobre a Mulher com tema central “Ação para a Igualdade, o Desenvolvimento e a Paz". Na Plataforma de Ação de Pequim afirmou os direitos das mulheres como direitos humanos e comprometidos com ações específicas para garantir o respeito a esses direitos. Definiu-se o conceito de gênero para a agenda internacional, empoderamento das mulheres e transversalidade das políticas públicas com a perspectiva de gênero. Para a ONU, "a transformação fundamental em Pequim foi o reconhecimento da necessidade de mudar o foco da mulher para o conceito de gênero, reconhecendo que toda a estrutura da sociedade, e todas as relações entre homens e mulheres dentro dela, tiveram que ser reavaliados. Só por essa fundamental reestruturação da sociedade e suas instituições poderiam as mulheres ter plenos poderes para tomar o seu lugar de direito como parceiros iguais aos dos homens em todos os aspectos da vida. Essa mudança representou uma reafirmação de que os direitos das mulheres são direitos humanos e que a igualdade de gênero era uma questão de interesse universal, beneficiando a todos". Foram, portanto, estabelecidas 12 áreas de preocupação sobre os direitos das mulheres e meninas, quais sejam: 1 . Mulheres e pobreza; 2. Educação e Capacitação de Mulheres; 3. Mulheres e Saúde; 4. Violência contra a Mulher; 5. Mulheres e Conflitos Armados; 6. Mulheres e Economia; 7. Mulheres no Poder e na liderança; 8. Mecanismos institucionais para o Avanço das Mulheres; 9. Direitos Humanos das Mulheres; 10. Mulheres e a mídia; 11. Mulheres e Meio Ambiente; 12. Direitos das Meninas.
} 
parecer absurdo e sem fundamentos legais para aqueles que conhecem o debate educacional, e também porque ele se espalha com muita força, não em debates acadêmicos, mas nas redes sociais. Esse discurso utiliza-se de uma linguagem próxima a do senso comum, recorrendo a dicotomias simplistas que reduzem questões complexas a falsas alternativas e valendo-se de polarizações já existentes no campo político para introduzi-las e reforçá-las no campo educacional. Os memes, imagens acompanhadas de breves dizeres, têm uma grande importância nesse discurso simplista.2 Então, nós não enfrentamos esse discurso e ele cresceu muito, até que projetos de lei, que incorporam as suas ideias, fossem apresentados nacionalmente e em vários estados do país e nos déssemos conta da ameaça real que ele representava (PENNA, 2017, p. 35).

Assim, percebendo o pouco alcance do seu ambicioso projeto, Nagib aliou-se aos Institutos neoliberais e absorveu outras pautas no Programa como, por exemplo, o combate à "ideologia de gênero", que já despontava no Congresso Nacional inúmeros Projetos de Lei com iniciativa da Frente Parlamentar Evangélica.

\section{A práxis ou atividade educativa como alternativa emancipadora}

Com relação às políticas públicas educacionais, Demerval Saviani e Newton Duarte (2012) reverbera o pensamento de que não houve nenhuma ruptura com a hegemonia da pedagogia do aprender a aprender e, que ao longo dos governos de Fernando Henrique e Lula, as políticas educacionais estiveram amoldadas para a reprodução de uma prática educativa sem qualquer relação com o trabalho educativo, enquanto espaço emancipatório.

Para a superação do modelo de educação como instrumento de reprodução da sociedade capitalista, é preciso pensar a "[...] educação escolar no contexto da luta de classes na atualidade" e compreender que a principal tarefa docente é " [...] dominar e transmitir aos seus alunos o 
conhecimento científico, artístico e filosófico em suas formas mais desenvolvidas" (SAVIANI; DUARTE, 2012, p. 161 e 165).

Saviani e Duarte (2012) também entendem que a educação não possui o condão de revolucionar a sociedade, entretanto constitui-se em importante campo estratégico, assim como analisa Mészáros (2008) sobre as vitais funções da educação para pensar numa sociedade verdadeiramente emancipada.

Neste sentido, a educação possui uma essência ontológica com a finalidade de compreender o processo pelo qual os indivíduos se tornam seres sociais. Ainda, "para que uma teoria marxista da educação possa ser também uma pedagogia marxista, é necessário assumir um posicionamento afirmativo sobre o que significa educar seres humanos hoje." (SAVIANI; DUARTE, 2012, p. 41). Deste modo, é preciso pensar sobre a prática educativa como momento de construção de uma condição para emancipação humana ${ }^{6}$

O modelo de processo educativo pensado, portanto, na perspectiva da totalidade demonstra a relação dialética intrínseca na produção dos saberes e o seu domínio pela classe dominante, na medida em que se acirra a divisão do trabalho. Quando o professor se apropria de uma metodologia pedagógica capaz de suplantar esta reprodução do modelo tradicional de aula, ele se nutre de uma percepção sobre a realidade capaz de identificar nas teorias pedagógicas impostas pelo

\footnotetext{
6 Acerca do conceito de emancipação humana e emancipação política muitos são os autores brasileiros que debatem sobre o tema, tomando como respaldo metodológico a teoria marxiana. Contudo, evidencia-se a distinção realizada por Ivo Tonet (2018, p. 90 1), que indaga “o que é emancipação humana? A palavra emancipação evoca, de modo muito geral, a ideia de liberdade. Essa liberdade pode ser entendida em sentido jurídico - a liberdade adquirida por menores de idade em relação aos seus pais ou tutores legais, - em sentido político - a liberdade obtida por uma nação ou região ou província face a outro poder político, - em sentido humano, isto é, a liberdade mais plena possível para o ser humano". Esta emancipação humana está associada à superação da sociedade de classes e de todas as formas de opressão/dominação; compreendendo que a simples emancipação política no bojo da sociedade capitalista equivale a conquista de liberdade nos limites impostos pela classe dominante. Continua Tonet, "quando Marx fala em emancipação humana está, claramente, se referindo a uma forma concreta de sociabilidade na qual a humanidade alcança o grau de liberdade mais amplo e profundo possível. Vale dizer, para Marx, emancipação humana equivale a sociedade comunista"
} 
ensino oficial o vazio preponderante e proposital. Este esvaziamento ocorre

À medida que a divisão do trabalho se desenvolve, a burguesia defende 'menos' a ruptura radical no 'domínio da ideias, apresentando os valores da Democracia, da Ciência, da Técnica, da Arte e da Cultura como entidades universais, válidas para sempre, para além das barreiras de classe e das formas de produção, o que permite denomina-las de slogans ou insígnia do capital, incluindo termos como cidadania, formação integral, cidadão crítico, dentre outros (ARNONI, 2018, p. 23-4).

Com relação à ruptura do modelo tradicional de ensino baseado na aula em seus moldes burgueses é preciso identificar estes "slogans" do capital postos como valores universais e promover a mediação dialética juntos aos alunos, enquanto atividade de entendimento da contradição instalada pela sociedade burguesa, o que se torna uma tarefa necessária para o docente do ensino básico atual. Estes termos estão presentes em toda a legislação educacional e, principalmente nos documentos oficiais com o objetivo de despertar "um sentimento de nacionalidade e, assim, 'compram a simpatia' do professor, induzindoo a pensar que ao usar o livro didático, por exemplo, desenvolverá os objetivos propostos pelos referidos termos" (ARNONI, 2018, p.24).

Pode-se valer também dos próprios eixos norteadores contidos nas Orientações Curriculares Nacionais (OCNs) para a disciplina de sociologia, qual seja de estranhamento (estranhar aquilo que é familiar, um olhar estranhado para o cotidiano) e desnaturalização (não naturalização das concepções a respeito dos fenômenos sociais) dos conhecimentos técnicos e científicos, "que a escola forma e informa para a formação de sujeitos conscientes, questionadores, críticos da sociedade que o circunda" (OCN, 2006, p. 105-6).

Como proposta de superação destas metodologias pedagógicas, a professora e pesquisadora Maria Eliza Brefere Arnoni (2010, 2012, 2014a, 2014b, 2018) desenvolveu o conceito de práxis ou atividade 
educativa via a proposição de uma teoria pedagógica crítica da Metodologia da Mediação Dialética - M.M.D., a partir dos elementos essenciais da categoria central do pensamento marxiano - o trabalho.

Desta categoria marxiana, a professora Arnoni (2010, 2012, 2014a, 2014b, 2018) valorizou os "seus elementos básicos, a intencionalidade, o objeto e o instrumental" (ARNONI, 2018, p. 19) para organizar o conceito de práxis ou atividade educativa, doravante apresentada apenas como atividade educativa.

Nesta proposta, segundo Arnoni, a mediação estabelecida entre professor e aluno no decorrer da atividade educativa se dá pela linguagem, por meio da qual, o professor estabelece a relação pedagógica da mediação dialética com o aluno, no desenvolvimento do conceito educativo, o objeto da atividade educativa, cuja unidade centra-se no processo educativo.

A atividade educativa alicerçada nos pressupostos teóricos da ontologia do ser social centra sua intencionalidade (teleologia) na compreensão da emancipação humana, como possibilidade de superar a emancipação política proclamada pelos documentos e legislações educacionais oficiais. Em verdade, a emancipação política visa à manutenção do sistema capitalista e a emancipação humana, por sua vez, é contra os ditames do capital (ARNONI, 2012, p.65-6).

A aula como práxis educativa e unidade da educação escolar cria um novo espaço de luta pela formação integral do aluno, por meio da qual possa perceber as contradições históricas que geraram o conhecimento aprendido, bem como sua vinculação com o contexto histórico, de forma a buscar transformações na vida particular e na práxis social.

Neste contexto, a compreensão teórico-metodológica da mediação dialético-pedagógica permite ao professor compreender a dimensão ontológica da aula como práxis educativa, entendendo-a como sua produção, algo que não lhe é estranho. Isto fortalece o professor no enfrentamento das condições impostas à educação escolar pelo capital, 
por meio de sua própria práxis educativa, ou seja, da aula como ato humano e consciente na luta pela emancipação humana. (ARNONI, 2012, p. 80).

Com isso, a atividade educativa está calcada nos fundamentos teóricos e metodológicos do método dialético marxiano ou materialismo histórico como "a possibilidade de propor a atividade humana educativa, identificando as similaridades entre ela e o trabalho, ambos, pautados na emancipação humana" (ARNONI, 2018, p. 26).

Arnoni e Silveira-Fossaluzza (2018, p. 79) acentua que o percurso científico apresentado está " pautado no entendimento que a essência da realidade educacional não se explicita no imediato, mas sim, via pesquisa teórica que compreende o fenômeno educativo como a síntese de múltiplas determinações históricas (im)postas".

Arnoni é norteada, assim, pelo "método dialético que, por meio das suas categorias, expressa o caminho teórico para compreender este mundo e a metodologia de ensino que se constitui no processo de aplicar as categorias do método dialético na práxis educativa" (ARNONI, 2012, p. 58) via a Metodologia da Mediação Dialética M.M.D.

Teoria Pedagógica da Metodologia da Mediação Dialética -M.M.D.

Sabe-se que, as propostas metodológicas hegemônicas e mercantilizadas por grupos empresariais ligados à educação são apresentadas como produtos às instituições de ensino públicas e privadas como fundamento para a relação de ensino e aprendizagem. Entretanto, a proposição teórico-metodológica para uma atividade educativa constitui-se como possibilidade do professor entender a prática da docência para além dos manuais pedagógicos articulados e apresentados como "receitas" sem qualquer questionamento ou construção conjunta, ou seja, permite que o professor compreenda "a 
dimensão ontológica da práxis educativa, entendendo-a como sua produção, algo que não lhe é estranho (ARNONI, 2014a, p. 113).

Arnoni, portanto, apresenta a Metodologia da Mediação Dialética - M.M.D. como um

instrumental da atividade educativa, por meio da qual, o professor desenvolve o objeto da atividade educativa, o conceito educativo, atendendo a intencionalidade consciente e previamente elaborada pelo professor [...] sendo uma alternativa teóricoprática, possível de ser desenvolvida pelo professor, em seu processo educativo, como enfrentamento às limitações que lhes são objetivamente postas pelo manual pedagógico oficial (ARNONI, 2018, p. 26-7).

O instrumental da atividade educativa, a proposição teóricometodológica da M.M.D. pauta-se nas categorias do método dialético totalidade, movimento, contradição, superação, momento predominante e mediação (ARNONI, 2010 e 2018), tendo a mediação como categoria central que articula as demais.

Deste modo, a proposição teórico-metodológica da atividade educativa consiste num importante instrumental que permite o enfrentamento do discurso hegemônico na educação escolar e para a defesa da Sociologia como componente curricular na grade no ensino médio. Trata-se de uma alternativa "para o professor desenvolver em sala de aula, nas brechas deixadas pelo sistema vigente", já que existe "a dificuldade [de] tal tarefa e a necessidade [de] não paralisa-se diante desta situação, pois, seria negar a contradição que rege o desenvolvimento do ser social, da sociedade capitalista e a totalidade do próprio universo" (ARNONI, 2018, p. 25).

São quatro Etapas distintas da proposição teórico-metodológica da M.M.D., desenvolvidas pela professora Maria Eliza Brefere Arnoni:

- RESGATAR é investigar as ideias iniciais que os alunos trazem em relação ao conceito ensinado, é o ponto de partida para o desenvolvimento do conceito educativo. O professor elabora, por diferentes 
linguagens, questões investigativas que abrangem: (a) o conceito a ser ensinado; (b) seus nexos internos; (c) seus nexos externos. Desenvolve-as com os alunos e analisa as respostas obtidas ou manifestação observadas nos alunos, tendo como parâmetro o conceito a ser ensinado e, conscientemente, opta por iniciar o processo educativo pelas ideias inicias dos alunos que guardam alguma relação com o conceito a ser ensinado. Importante é preservar o princípio básico desta proposição, o aluno só entende a fala do professor se possuir esquema cognitivo que lhe permita estabelecer relações com o conceito, em questão. Os dados obtidos são utilizados para o professor organizar a Etapa seguinte da M.M.D.,

- PROBLEMATIZAR é explicitar subjetivamente uma contradição e, para isso, é necessário colocar o aluno em uma situação desafiadora capaz de levá-lo mentalmente a perceber as diferenças entre suas ideias iniciais e o conceito desenvolvido pelo professor. Como o conceito, em sua totalidade, expressa um todo formado pelas relações dialéticas entre as partes que o compõem e, destas, com o todo, para explicitar a contradição, o foco da questãoproblema refere-se à parte, se os dados do Resgatando voltam-se para o todo do conceito. E, o foco refere-se ao todo, se os dados do Resgatando voltarem-se às partes do conceito, seus nexos internos. A contradição, a luta dos contrários, constitui-se na fonte fundamental do desenvolvimento da consciência, assim, a questão poblematizadora é o despertar da consciência do que é aprender. As reações, manifestação ou registros dos alunos, são os elementos para a elaboração da Etapa seguinte da M.M.D.

- SISTEMATIZAR é o ato mental do aluno, ao superar as ideias iniciais na elaboração do conceito ensinado. Isto lhe é potencializado pelo professor quando retoma a questão-problema, discutindo-a, por meio de informações conceituais que possibilitem ao aluno compreender as relações de sentido entre aspectos de suas ideias iniciais e elementos do conceito ensinado, 
a elaboração de sínteses, o que lhe permite desenvolver a Etapa seguinte da M.M.D.

- PRODUZIR é o momento de o aluno expressar as sínteses cognitivas elaboradas no desenvolvimento da M.M.D., por meio de diferentes linguagens, o que permite ao professor compará-las com as ideias iniciais dos alunos. Como a produção final, a síntese conceitual, apresenta-se mais elaborada que as ideias iniciais, o Produzindo torna-se imediatamente o Resgatando de um novo conceito, e, assim, o ciclo não se fecha, ao contrário, ele forma no pensamento do aluno, a espiral do conhecimento, contínua e eterna. Ou seja, se a análise do texto final demonstrar que houve superação das ideias iniciais, o Produzir torna-se imediatamente um novo Ponto de partida, o Resgatando, gerando o movimento em espiral. Caso a análise demonstra que não houve superação, é recomendável ao professor planejar, desenvolver e analisar novamente a prática educativa. (ARNONI, 2018, p. 82-3). 
Imagem 1 - Diagrama da Metodologia da Mediação Dialética - M.M.D

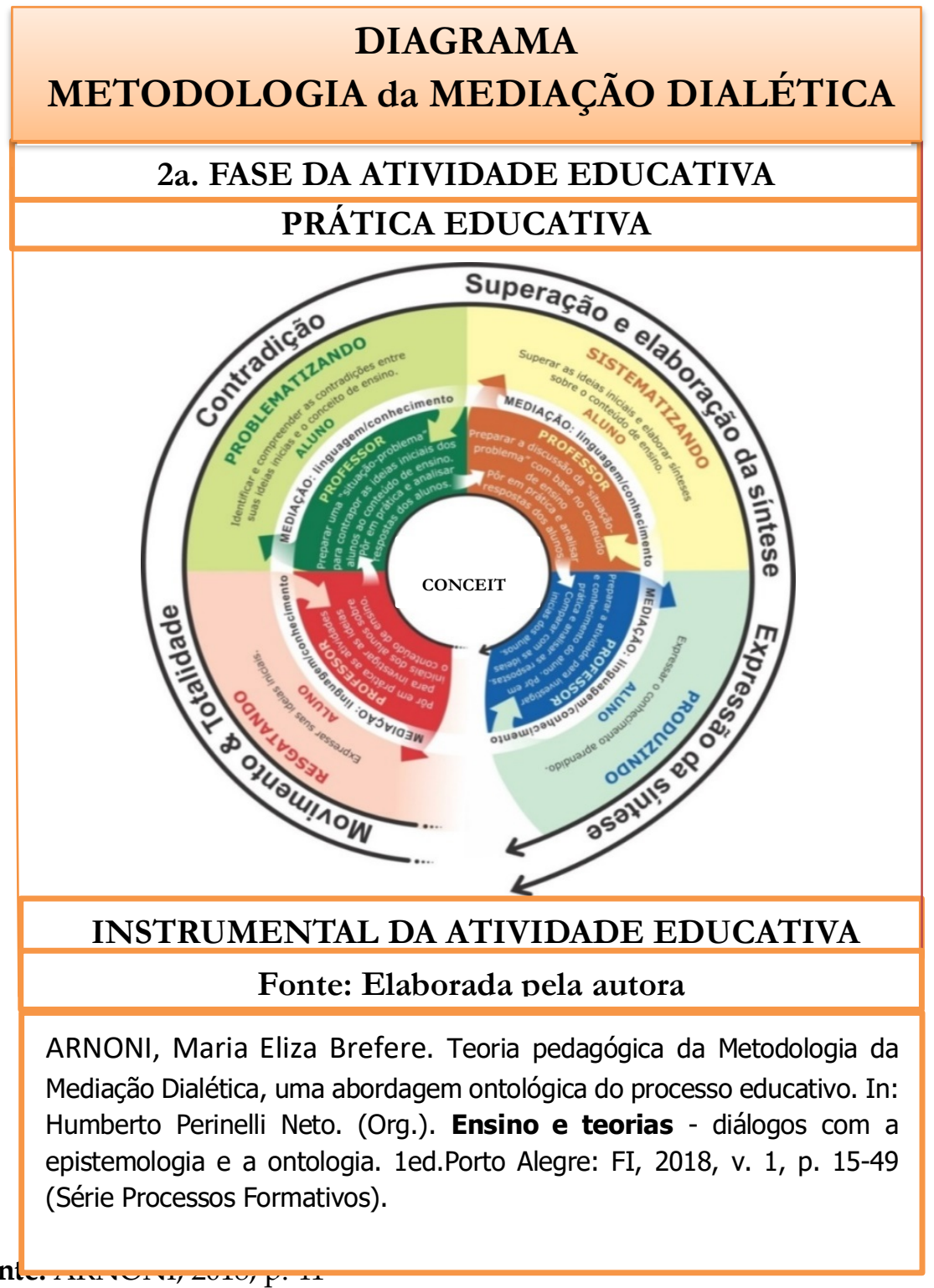

Cada etapa da M.M.D. expressa a execução de categorias do método marxiano (totalidade, movimento, contradição, superação e 
momento predominante) relacionando-se dialeticamente na atividade de mediação.

Observa-se, que o conceito educativo encontra-se no centro de todas as Etapas da M.M.D., pois elas desenvolvem o mesmo conceito, entretanto qualitativamente diferente. $\mathrm{Na} 1^{\mathrm{a}}$ etapa, as ideias iniciais do aluno constituem o Resgatando, a partir das quais o professor percorrerá até a $4^{\mathrm{a}}$ Etapa do Produzindo, na qual, por diferentes linguagens, o aluno exterioriza sua produção intelectual, via superação das ideias iniciais, a qual torna-se, imediatamente, um novo Resgatando, dando origem ao desenvolvimento das demais etapas metodológicas da M.M.D., gerando o movimento característico da elaboração intelectual do aluno, em espiral, um movimento contínuo e eterno.

\section{Conclusões}

À guisa de conclusão, o trabalho apresentado possui o fito de suscitar uma inquietação em docentes do ensino básico e cientistas, já que professores e professoras do ensino básico e do ensino superior são postos como verdadeiros vilões e responsáveis pela transformação da juventude brasileira, a qual no julgamento desta elite econômica e religiosa fundamentalista, está sendo desviada do caminho da normalidade. O que possui, hoje, é o acesso dos jovens a muitos outros mecanismos para conhecer e expressar as suas identidades, inclusive de gênero.

Nesse sentido, pode-se observar a estreita relação entre o Estado, a Sociedade e Religiões, sendo que esta é, historicamente, mascarada sob o signo da laicidade do Estado. Sob o discurso moralizante de defesa da família brasileira grupos de políticos guinados a direita e ligados ao fundamentalismo religioso preparam um terreno fértil para promover políticas educacionais esvaziadas de sentido humano. Ainda, disseminam a indispensabilidade do projeto privatista e de 
militarização para a educação brasileira como sinônimo de resgate da função social da instituição escolar.

Com isso, ganha destaque a análise da atividade educativa através da proposição da Metodologia da Mediação Dialética - M.M.D. (ARNONI, 2012, 2014, 2014a, 2018) como enfrentamento da hegemonia burguesa instalada na educação brasileira relativo à defesa da existência, de fato, de uma "ideologia de gênero" propugnada pelos professores.

\section{Referências}

ARNONI, Maria Elisa Brefere. Metodologia da Mediação Dialética na organização da atividade educativa: Educação em Ciências. In: GOIS, J. (Org.). Metodologias e Processos Formativos em Ciências e Matemática. Paco Editorial: Jundiaí, 2014a. p. 99-119.

ARNONI, Maria Elisa Brefere. Análise histórico-ontológica da aula: uma introdução à práxis educativa. Seminário Internacional da REDE ESTRADO Direito à Educação, políticas educativas e trabalho docente na América Latina. Experiências e propostas em disputa. X. Salvador, 2014b. Anais [...]. X SEMINÁRIO DE LA RED ESTRADO de Salvador, 2014b. CD-ROM.ISSN 2219685-4. 17p.

ARNONI, Maria Elisa Brefere. Mediação dialético-pedagógica e práxis educativa: o aspecto ontológico da aula. Revista Educação e Emancipação, São Luís/MA, v. 5, n. 2, p. 58-82, jul./dez. 2012.

ARNONI, Maria Elisa Brefere. Questões teóricas e metodológicas da aula no contexto atual: enfrentamentos da práxis educativa. VIII Seminário Internacional da REDE ESTRADO "Educação e Trabalho Docente no novo cenário latino-americano: entre a mercantilização e a democratização do conhecimento". Lima. Peru. 2010. ISNN 22196854. 15p.

ARNONI, Maria Eliza Brefere. Teoria pedagógica da metodologia de mediação dialética, uma abordagem ontológica do processo educativo. In: PERINELLI NETO, Humberto (Org.). Ensino e teorias: diálogos com a epistemologia e a ontologia. 1 ed. Porto Alegre: FI, 2018. p. 21-56. v. 1. (Série Processos Formativos). 
ARNONI, Maria Eliza Brefere; SILVEIRA-FOSSALUZZA Juliana Tiburcio. Ensino\&Aprendizagem como objeto de pesquisa na educação: aprimoramento da atividade educativa. In: FORTUNATO, Ivan; SHIGUNOV NETO, Alexandre (Org.). Método(s) de Pesquisa em Educação. São Paulo: Edições Hipótese, 2018. 100p. ISBN: 978-85924379-9-2. p. 77-92.

BRASIL. Base Nacional Comum Curricular. Homologada pelo Ministro da Educação, Rossieli Soares, em 14 de dezembro de 2018, documento da Base Nacional Comum Curricular para a etapa do Ensino Médio. Brasília: Ministério da Educação, 2018. 595 p.

BRASIL. Câmara dos Deputados. Projeto de Lei PL no 7180, de 2014, do Sr. Erivelton Santana. Altera o art. $3^{\circ}$ da Lei $n^{\circ}$ 9.394, de 20 de dezembro de 1996. Brasília. Disponível em: www.camara.leg.br/proposicoesWeb/fichadetramitacao?idProposic $\mathrm{ao}=606722$. Acesso em: 21 de mar. 2019.

BRASIL. Secretaria de Educação Básica. Ministério da Educação. Orientações Curriculares para o Ensino Médio - Ciências Humanas e suas Tecnologias. Brasília, 2006. Disponível em: http:// portal.mec.gov.br/seb/arquivos/pdf/book_volume_03_inter net.pdf. Acesso em: 22 de jul. 2018.

LOZANO, José Ruy. Educação: entre histéricos, demagogos, financistas. Le Monde Diplomatique - Brasil, São Paulo, ano 12, n. 134, p. 10, set. 2018.

MACHADO, Maria das Dores Campos. O discurso cristão sobre a "ideologia de gênero". Revista Estudos Feministas, Florianópolis, v. 26, n. 2, 2018.

MÉSZÁROS, István. A Educação para além do Capital. 2. ed. São Paulo: Boitempo, 2008.

MÉSZÁROS, István. O Poder da Ideologia. São Paulo: Boitempo, 2004.

PENNA, Fernando. "Escola sem Partido" como ameaça à Educação Democrática: fabricando o ódio aos professores e destruindo o potencial educacional da escola. In: MACHADO, André Roberto; TOLEDO, Maria Rita de Almeida (Org.). Golpes na história e na escola: o Brasil e a América Latina nos séculos XX e XXI. São Paulo: Cortez: ANPUH SP, 2017. 
REIS, Toni; EGGERT, Edla. Ideologia de gênero: uma falácia construída sobre os Planos de Educação brasileiros. Educação $\mathcal{E}$ Sociedade, Campinas, v. 38, n. 138, p. 9-26, jan./mar. 2017.

RICOEUR, Paul. Tempo e Narrativa. Campinas: Papirus, 1994. Tomo I.

SILVA, André Luiz Batista; SOUZA, Maria Antônia. Movimentos conservadores no âmbito da educação no Brasil: disputas que marcaram a conjuntura de 2014 a 2018. Revista Crítica Educativa, Dossiê: Movimentos Sociais Conservadores e Educação, v. 4, n. 2, p. 07-23, jul./dez. 2018.

TONET, Ivo. A problemática da emancipação humana, da revolução e do comunismo. In: Marxismo, Religiosidade e Emancipação Humana. Maceió: Coletivo Veredas, 2019, p. 89-109. 